\title{
Article \\ In Vivo Transcutaneous Monitoring of Hemoglobin Derivatives Using a Red-Green-Blue Camera-Based Spectral Imaging Technique
}

\author{
Fahima Khatun ${ }^{1,2}$, Yoshihisa Aizu ${ }^{3}$ and Izumi Nishidate ${ }^{1, *}$ \\ 1 Graduate School of Bio-Applications \& Systems Engineering, Tokyo University of Agriculture and \\ Technology, Koganei 184-8588, Japan; s186125v@st.go.tuat.ac.jp \\ 2 Department of Pathobiology, Faculty of Veterinary Medicine and Animal Science, Banghabandhu Sheikh \\ Mujibur Rahman Agricultural University, Gazipur 1706, Bangladesh; fahimabau@gmail.com \\ 3 College of Design and Manufacturing Technology, Muroran Institute of Technology, Muroran 050-8588, Japan; \\ aizu@mmm.muroran-it.ac.jp \\ * Correspondence: inishi@cc.tuat.ac.jp; Tel.: +81-42-388-7065
}

Citation: Khatun, F.; Aizu, Y.; Nishidate, I. In Vivo Transcutaneous Monitoring of Hemoglobin Derivatives Using a Red-Green-Blue Camera-Based Spectral Imaging Technique. Int. J. Mol. Sci. 2021, 22, 1528. https://doi.org/10.3390/ ijms22041528

\section{Academic Editor:}

Joan Roselló-Catafau

Received: 28 December 2020

Accepted: 1 February 2021

Published: 3 February 2021

Publisher's Note: MDPI stays neutral with regard to jurisdictional claims in published maps and institutional affiliations.

Copyright: (c) 2021 by the authors. Licensee MDPI, Basel, Switzerland. This article is an open access article distributed under the terms and conditions of the Creative Commons Attribution (CC BY) license (https:// creativecommons.org/licenses/by/ $4.0 /)$.

\begin{abstract}
Cyanosis is a pathological condition that is characterized by a bluish discoloration of the skin or mucous membranes. It may result from a number of medical conditions, including disorders of the respiratory system and central nervous system, cardiovascular diseases, peripheral vascular diseases, deep vein thrombosis, and regional ischemia. Cyanosis can also be elicited from methemoglobin. Therefore, a simple, rapid, and simultaneous monitoring of changes in oxygenated hemoglobin and deoxygenated hemoglobin is useful for protective strategies against organ ischemic injury. We previously developed a red-green-blue camera-based spectral imaging method for the measurements of melanin concentration, oxygenated hemoglobin concentration $\left(C_{\mathrm{HbO}}\right)$, deoxygenated hemoglobin concentration $\left(C_{\mathrm{HbR}}\right)$, total hemoglobin concentration $\left(C_{\mathrm{HbT}}\right)$ and tissue oxygen saturation $\left(\mathrm{StO}_{2}\right)$ in skin tissues. We leveraged this approach in this study and extended it to the simultaneous quantifications of methemoglobin concentration $\left(C_{\mathrm{metHb}}\right), C_{\mathrm{HbO}}$, $\mathrm{C}_{\mathrm{HbR}}$, and $\mathrm{StO}_{2}$. The aim of the study was to confirm the feasibility of the method to monitor $\mathrm{C}_{\text {metHb}}, \mathrm{C}_{\mathrm{HbO}}, \mathrm{C}_{\mathrm{HbR}}, \mathrm{C}_{\mathrm{HbT}}$, and $\mathrm{StO}_{2}$. We performed in vivo experiments using rat dorsal skin during methemoglobinemia induced by the administration of sodium nitrite $\left(\mathrm{NaNO}_{2}\right)$ and changing the fraction of inspired oxygen $\left(\mathrm{FiO}_{2}\right)$, including normoxia, hypoxia, and anoxia. Spectral diffuse reflectance images were estimated from an RGB image by the Wiener estimation method. Multiple regression analysis based on Monte Carlo simulations of light transport was used to estimate $\mathrm{C}_{\mathrm{HbO}}$, $\mathrm{C}_{\mathrm{HbR}}, \mathrm{C}_{\mathrm{metHb}}, \mathrm{C}_{\mathrm{HbT}}$, and $\mathrm{StO}_{2} . \mathrm{C}_{\mathrm{metHb}}$ rapidly increased with a half-maximum time of less than $30 \mathrm{~min}$ and reached maximal values nearly $60 \mathrm{~min}$ after the administration of $\mathrm{NaNO}_{2}$, whereas $\mathrm{StO}_{2}$ dramatically dropped after the administration of $\mathrm{NaNO}_{2}$, indicating the temporary production of methemoglobin and severe hypoxemia during methemoglobinemia. Time courses of $C_{\mathrm{HbT}}$ and $\mathrm{StO}_{2}$, while changing the $\mathrm{FiO}_{2}$, coincided with well-known physiological responses to hyperoxia, normoxia, and hypoxia. The results indicated the potential of this method to evaluate changes in skin hemodynamics due to loss of tissue viability and vitality.
\end{abstract}

Keywords: oxygenated hemoglobin; deoxygenated hemoglobin; methemoglobin; tissue oxygen saturation; wiener estimation method; spectral imaging; multiple regression analysis; Monte Carlo simulation

\section{Introduction}

A patient with a bluish discoloration in the skin, known as cyanosis, is alarming to a medical doctor. Such cases may be severely hypoxemic or hypoxic, constituting a medical emergency [1]. Cyanosis first appears in the extremities when oxygen demand outstrips the supply, resulting in a high amount of deoxygenated blood accumulating in blood-perfused 
dermal tissues [2,3]. This may result from a number of medical conditions, including reduced cardiac output (heart failure), peripheral vasoconstriction (hypothermia), and regional ischemia (arterial thrombosis) [1,4,5]. Cyanosis can also be elicited from dysfunctional forms of hemoglobin, such as methemoglobin (metHb) [2,6,7]. Methemoglobin is an abnormal form of hemoglobin that oxidizes iron molecules within hemoglobin $[6,8,9]$. Figure 1 shows the extinction coefficient spectra of typical hemoglobin derivatives and melanin at visible wavelengths between 400 and $700 \mathrm{~nm}$ [10-12].

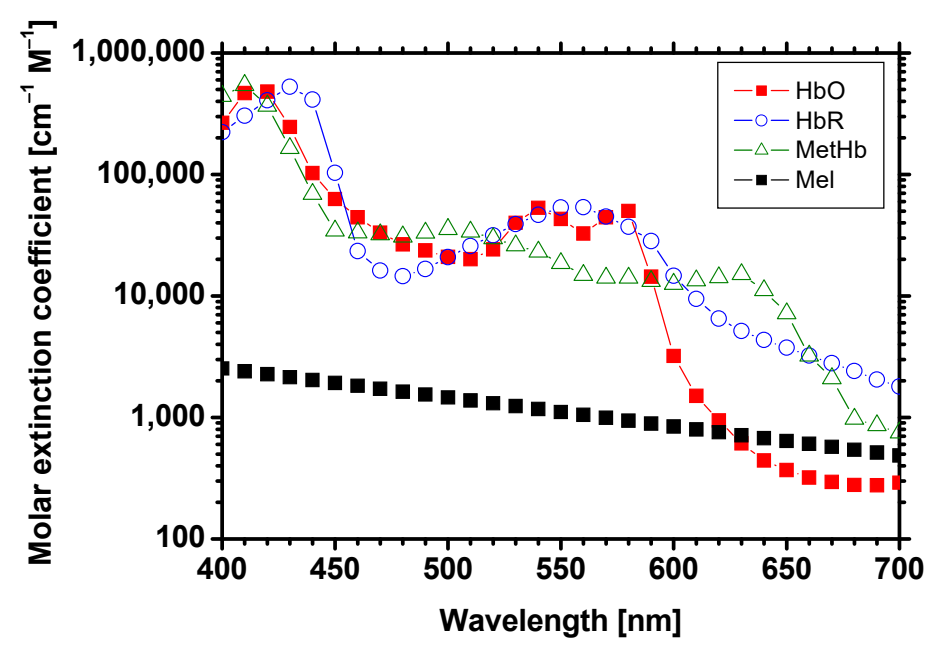

Figure 1. Extinction coefficient spectra of typical hemoglobin derivatives (oxygenated hemoglobin $\mathrm{HbO}^{10}$, deoxygenated hemoglobin $\mathrm{HbR}^{10}$, and methemoglobin ${ }^{11}$ ) and melanin ${ }^{12}$ in visible wavelength region between 400 and $700 \mathrm{~nm}$.

The absorption spectrum of hemoglobin depends primarily on whether or not the blood is oxygenated. Thus, there are two main derivatives, i.e., oxyhemoglobin in oxygenated blood and deoxyhemoglobin in deoxygenated blood. There are also hemoglobin derivatives that are incapable of transporting oxygen molecules. These are collectively known as dyshemoglobins, which include methemoglobin, carboxyhemoglobin, and sulfhemoglobin. The absorption can differ drastically between dysfunctional hemoglobin and functional hemoglobin [13,14]. Methemoglobin is unable to bind oxygen, so if a large amount of an individual's hemoglobin is converted to methemoglobin, tissue oxygenation is impaired. Furthermore, increased fractions of methemoglobin shift the oxygen dissociation curve to the left, which further impairs tissue oxygenation [15,16]. Given the low partial pressure of oxygen, hypoxia ensues $[17,18]$. In a normal human subject, less than $1-2 \%$ methemoglobin is present [6]. An abnormal level of methemoglobin (methemoglobinemia) may result from congenital enzyme deficiencies $[9,19]$ or exposure to certain chemicals and medications turning hemoglobin into a dysfunctional form of hemoglobin [20-24]. These chemical agents include drugs used in hospitals and health care settings, such as some local anesthetics (e.g., benzocaine and lidocaine [20-22]) and antibiotics (e.g., dapsone [23]), as well as nitrates and nitrites present in fertilizers that may contaminate food and water supplies [24,25]. The initial symptoms appear as a bluish discoloration of the skin when the methemoglobin level is at least $10-20 \%$ of the total hemoglobin [6-26]. This is potentially life threatening and a high mortality rate is often observed when the methemoglobin percentage exceeds $70 \%$ [6-26]. While, in many cases, methemoglobinemia is reversible after treating with methylene blue [27], some unusual cases do not respond to this substance [28]. Therefore, the evaluation of methemoglobin concentration is important for clinical applications. Furthermore, information on the spatial distribution of methemoglobin would aid in the diagnosis and treatment of diseases. The fast measurement of methemoglobin is very important to surgeons when anesthetics are applied, allowing them to react quickly by revealing the concentration change following the treatment. Moreover, it provides information for differential diagnoses in patients with 
mechanical airway obstruction or pulmonary embolus [29], and in infants with congenital cyanosis or sepsis [9].

Current devices, such as co-oximeters and blood gas analyzers, are frequently applied to evaluate the abnormal presence of methemoglobin in blood samples [30]. The readings provided by co-oximeters often provide false positives in the presence of sulfhemoglobin and methylene blue [31,32]. The arterial blood gas analyzer only measures dissolved oxygen, and not the actual amount of oxygen bound to hemoglobin in the blood. This also results in a false positive diagnosis for methemoglobinemia even though the met $\mathrm{Hb}$ concentration is high $[9,31]$. In addition to these two methods, other techniques, such as broadband optical spectroscopy [33-36] and photoacoustic imaging $[37,38]$ have the potential for the non-invasive in vivo monitoring of methemoglobin absorption properties.

Diffuse reflectance spectroscopy (DRS) has been utilized for the evaluation of skin chromophores (melanin, oxygenated hemoglobin and deoxygenated hemoglobin) [39-41] and tissue oxygen saturation [39,41,42]. Multi-spectral imaging, based on DRS, has been extensively researched for evaluating the spatial distribution of chromophore content in living tissue [43-45]. On the other hand, the reconstruction of multispectral images from a red/green/blue (RGB) image acquired by a digital RGB camera is a promising method for performing rapid and cost-effective multispectral imaging. Several reconstruction techniques for multispectral images, such as the pseudo-inverse method [46-49], finitedimensional modeling [48,50], nonlinear estimation method [51], and Wiener estimation method (WEM) [52-55] have been studied. Among these reconstruction techniques, the WEM is one of the most promising methods for the establishment of a compact and affordable imaging system that can simultaneously evaluate the spatiotemporal distributions of chromophores in clinical point-of-care testing due to its simplicity, cost-effectiveness, accuracy, time efficiency, and possibility of high-resolution image acquisition. Such a device would have an enormous impact on the health of people of all ages worldwide.

In the existing literature, a spectral imaging method based on the WEM has been proposed for the measurements of melanin, oxygenated hemoglobin, and deoxygenated hemoglobin in skin tissues. The WEM has also been applied to the visualization of spatiotemporal changes in peripheral hemodynamics in response to physiological stimuli [56]. In this approach, multiple regression analysis is performed by using the spectral image reconstructed by the WEM at wavelengths between 500 and $600 \mathrm{~nm}$ as a response variable and the known extinction coefficient spectra of melanin, oxygenated hemoglobin, and deoxygenated hemoglobin as predictor variables to provide multiple regression coefficients. The concentrations of melanin and hemoglobin are then determined from the regression coefficients using empirical formulae that are deduced numerically in advance. A Monte Carlo simulation (MCS) of light transport in a human skin model is carried out to numerically establish the empirical formulae. We leveraged this approach in our study and extended it to the simultaneous quantification of methemoglobin, oxygenated hemoglobin, and deoxygenated hemoglobin. Multispectral diffuse reflectance images of in vivo skin are estimated from an RGB image captured by a digital RGB camera. An MCS-based multiple regression analysis for the estimated absorbance spectra at 16 wavelengths (500 to $650 \mathrm{~nm}$ at $10 \mathrm{~nm}$ intervals) is then used to quantify the chromophore concentrations. In order to confirm the feasibility of this method to evaluate chromophore concentrations, we performed in vivo experiments using rat dorsal skin during methemoglobinemia induced by the administration of sodium nitrite $\left(\mathrm{NaNO}_{2}\right)$ and changing the fraction of inspired oxygen $\left(\mathrm{FiO}_{2}\right)$, including normoxia, hypoxia, and anoxia.

\section{Results}

Figure 2 shows typical spectral reflectance images estimated from the RGB image of in vivo rat dorsal skin under normal conditions by the WEM. Spectral reflectance images of the skin were successfully reconstructed from the RGB image using the proposed method. Figure 3 shows the reflectance spectra estimated using the WEM and the reflectance spectra measured by the spectrometer (a) before the administration of $\mathrm{NaNO}_{2}$, (b) 60 min after the 
administration of $\mathrm{NaNO}_{2}$, (c) 120 min after the administration of $\mathrm{NaNO}_{2}$, and (d) 360 min after the administration of $\mathrm{NaNO}_{2}$. The reflectance spectra estimated using the WEM are comparable to the spectra measured by the spectrometer for the different time points. The estimated spectra after the administration of $\mathrm{NaNO}_{2}$ are dominated by the spectral characteristics of methemoglobin. The values of the goodness-of-fit coefficient (GFC) obtained from four rats after the administration of $\mathrm{NaNO}_{2}$ summarized in Table 1 indicate an accurate spectral reconstruction by the WEM.

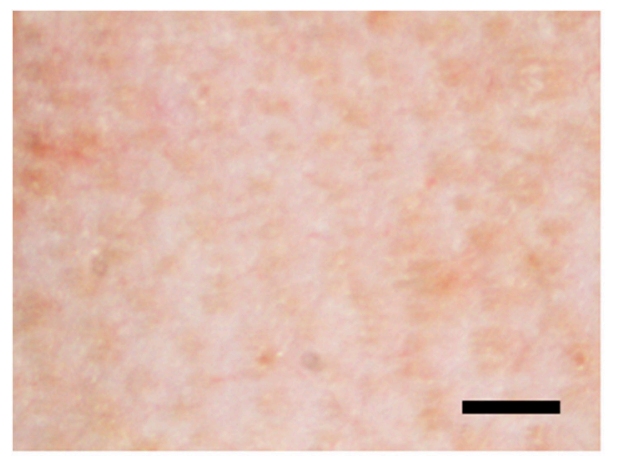

(a)

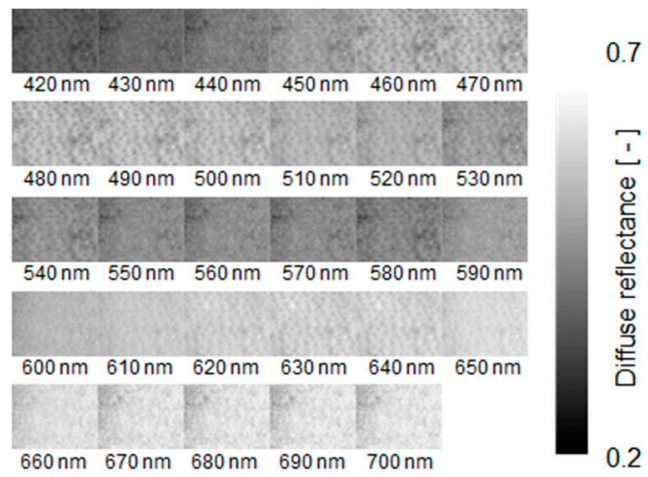

(b)

Figure 2. Typical results obtained from in vivo rat dorsal skin under normal conditions: (a) raw RGB image and (b) estimated images of spectral diffuse reflectance by Wiener estimation. A scale bar (black line in the RGB image) indicates $1.0 \mathrm{~mm}$.

(a)

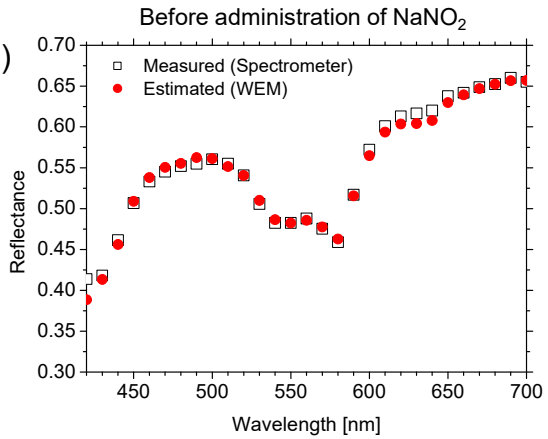

(c)

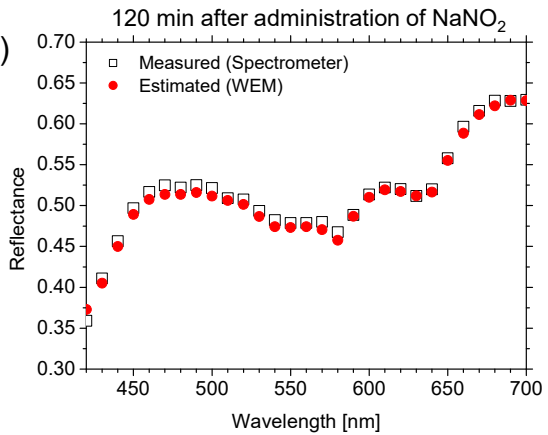

(b)

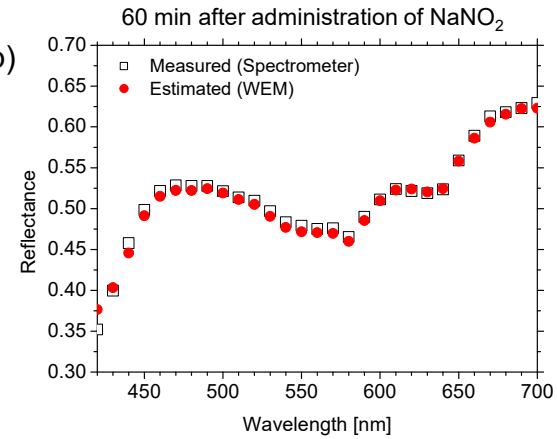

(d)

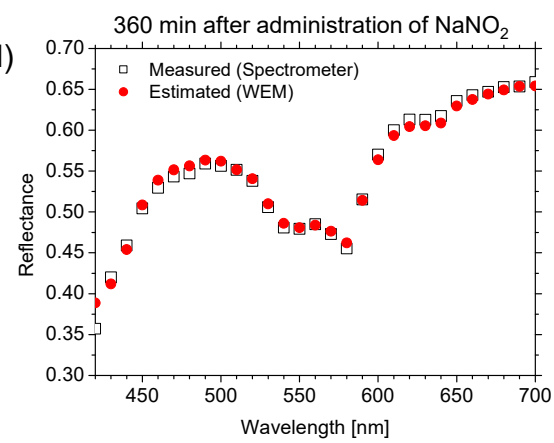

Figure 3. Comparisons of estimated reflectance spectra averaged over entire region of spectral images and reference spectra measured by spectrometer: (a) before administration of $\mathrm{NaNO}_{2}$, (b) 60 min after administration of $\mathrm{NaNO}_{2}$, (c) 120 min after administration of $\mathrm{NaNO}_{2}$, and (d) 360 min after administration of $\mathrm{NaNO}_{2}$. 
Table 1. Goodness-of-fit coefficient (GFC) obtained from four rats during methemoglobinemia.

\begin{tabular}{ccccccc}
\hline \multicolumn{7}{c}{ Goodness-of-Fit Coefficient (GFC) } \\
\hline Rat & Mean & \pm SD & Max & Min & Number of Spectra & Accuracy \\
\hline$\# 1$ & 0.9990 & 0.0006 & 0.9999 & 0.9972 & 339 & Good \\
$\# 2$ & 0.9996 & 0.0002 & 0.9999 & 0.9998 & 359 & Good \\
$\# 3$ & 0.9999 & 0.0001 & 0.9999 & 0.9995 & 363 & Excellent \\
$\# 4$ & 0.9993 & 0.0003 & 0.9999 & 0.9982 & 358 & Good \\
\hline
\end{tabular}

Figure 4 shows typical sequential images of (a) $\mathrm{C}_{\mathrm{metHb}}$, (b) $\mathrm{C}_{\mathrm{HbT}}$, (c) $\mathrm{StO}_{2}$, and (d) $\mathrm{C}_{\mathrm{m}}$ obtained from rat dorsal skin before and after the administration of $\mathrm{NaNO}_{2}$ at a dose of $50 \mathrm{mg} / \mathrm{kg}$. Figure 5 shows the typical time courses of (a) $\Delta C_{\text {metHb }}$, (b) $\Delta C_{\mathrm{HbT}}$, (c) $\Delta S t \mathrm{O}_{2}$, and (d) $\Delta C_{m}$ averaged over the entire region of each estimated image. $C_{m e t H b}$ increased after the administration of $\mathrm{NaNO}_{2}$ and returned to normal levels at $360 \mathrm{~min}$ after the administration of $\mathrm{NaNO}_{2}$. The value of $\mathrm{StO}_{2}$ decreased after the administration of $\mathrm{NaNO}_{2}$, indicating temporary hypoxemia caused by methemoglobinemia. There was a profound increase in $\mathrm{C}_{\mathrm{HbT}}$ after the administration of $\mathrm{NaNO}_{2}$. In spite of the remarkable changes in $\mathrm{C}_{\mathrm{metHb}}, \mathrm{C}_{\mathrm{HbT}}$ and $\mathrm{StO}_{2}, \mathrm{C}_{\mathrm{m}}$ remained almost unchanged during the measurements.

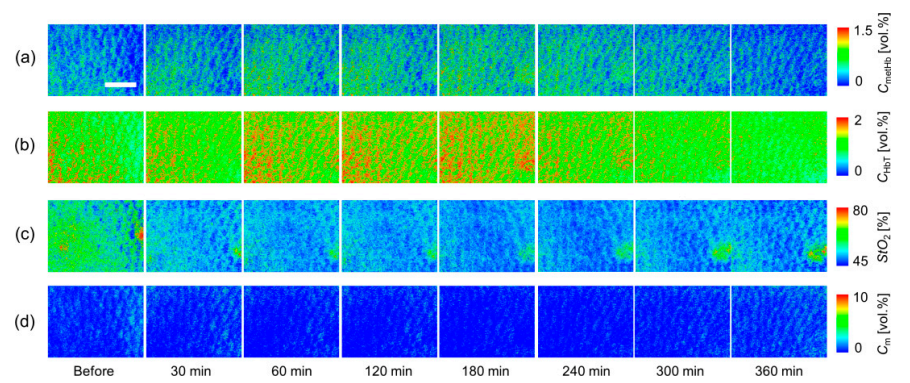

Figure 4. Typical sequential images of (a) $\mathrm{C}_{\text {metHb }}$, (b) $\mathrm{C}_{\mathrm{HbT}}$, (c) $\mathrm{StO}_{2}$, and (d) $\mathrm{C}_{\mathrm{m}}$ obtained from rat dorsal skin before and after the administration of $\mathrm{NaNO}_{2}$ at dose of $50 \mathrm{mg} / \mathrm{kg}$. A scale bar (white line in the $C_{\text {metHb }}$ image for before) indicates $2.0 \mathrm{~mm}$.
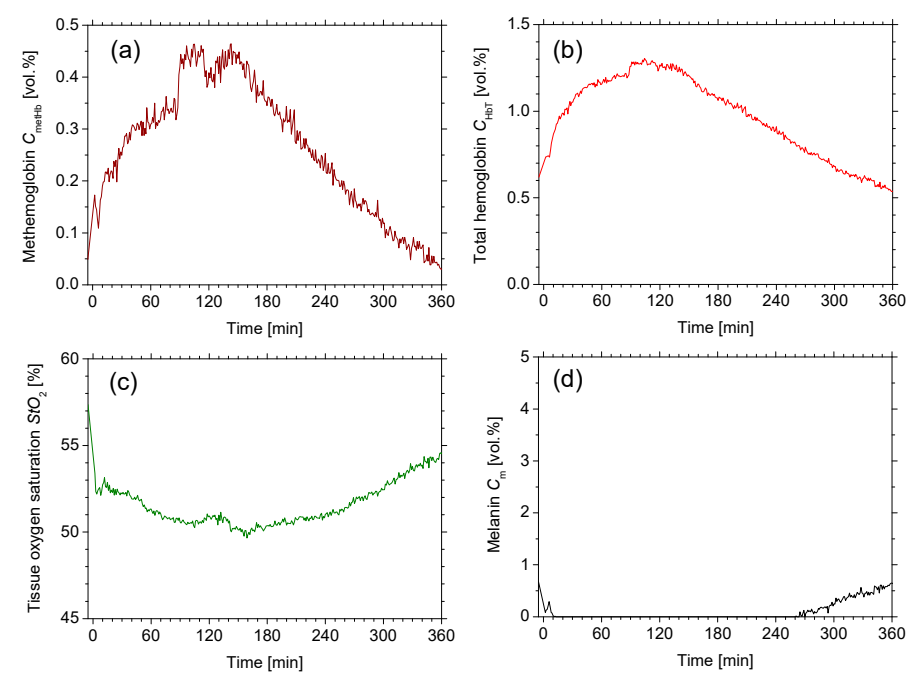

Figure 5. Typical time courses of (a) $\mathrm{C}_{\mathrm{metHb}}$, (b) $\mathrm{C}_{\mathrm{HbT}}$, (c) $S t \mathrm{O}_{2}$, and (d) $\mathrm{C}_{\mathrm{m}}$ averaged over entire region of each estimated image.

Figure 6 shows the time courses of (a) $\Delta C_{\text {metHb}}$, (b) $\Delta C_{\mathrm{HbT}}$, and (c) $\Delta S t \mathrm{O}_{2}$ averaged over two rats for different doses of $\mathrm{NaNO}_{2}$. The values of $\Delta C_{\text {metHb }}$ rapidly increased with a half-maximum time of less than $30 \mathrm{~min}$, and the time required to return to the normal levels increased proportionally with the dose. On the other hand, for each dose condition, the 
time course of $\Delta S t \mathrm{O}_{2}$ dramatically dropped at 120 min after the administration of $\mathrm{NaNO}_{2}$, and then gradually increased again. The values of $\Delta \mathrm{StO}_{2}$ were negatively correlated to those of $\Delta C_{\text {metHb }}$.

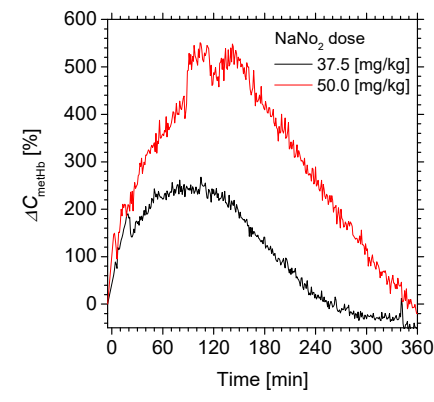

(a)

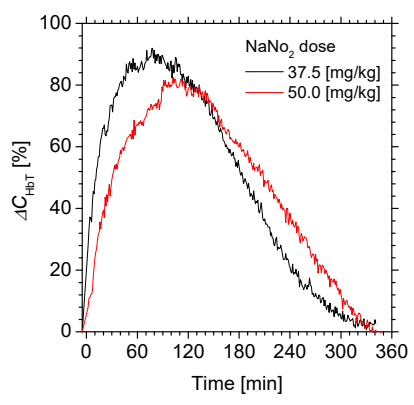

(b)

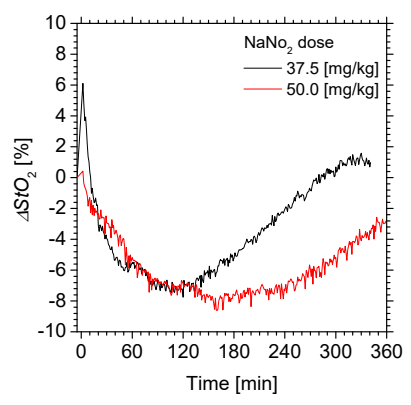

(c)

Figure 6. Time courses of (a) $\Delta C_{\text {metHb }}$, (b) $\Delta C_{\mathrm{HbT}}$, and (c) $\Delta S t \mathrm{O}_{2} \Delta C_{\mathrm{m}}$ averaged over two rats for different doses of $\mathrm{NaNO}_{2}$.

Figure 7 shows the reflectance spectra estimated using the WEM and the reflectance spectra measured by the spectrometer for (a) hyperoxia $\left(\mathrm{FiO}_{2}=40 \%\right)$, (b) normoxia $\left(\mathrm{FiO}_{2}=21 \%\right)$, (c) hypoxia $\left(\mathrm{FiO}_{2}=5 \%\right)$, and (d) anoxia $\left(\mathrm{FiO}_{2}=0 \%\right)$. The reflectance spectra estimated using the WEM are comparable to the spectra measured by the spectrometer for the different time points. The estimated spectra at hyperoxia and hypoxia are dominated by the spectral characteristics of oxygenated hemoglobin and deoxygenated hemoglobin, respectively. The values of GFC obtained from three rats while changing $\mathrm{FiO}_{2}$ are summarized in Table 2, which indicates a successful spectral reconstruction by the WEM.

(a)

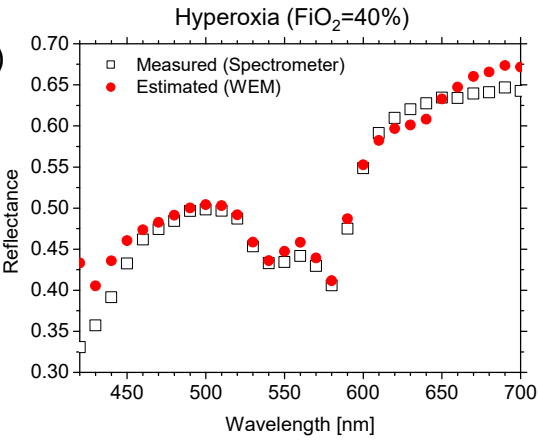

(c)

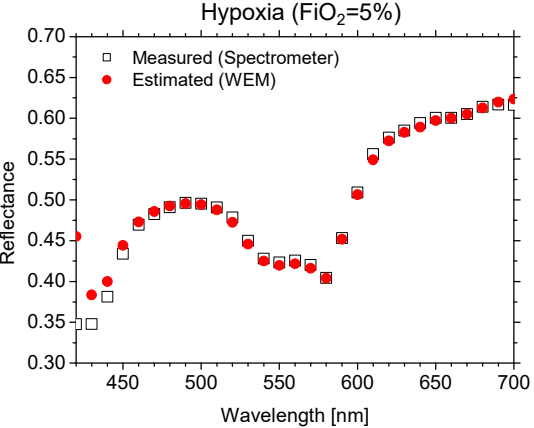

(b)

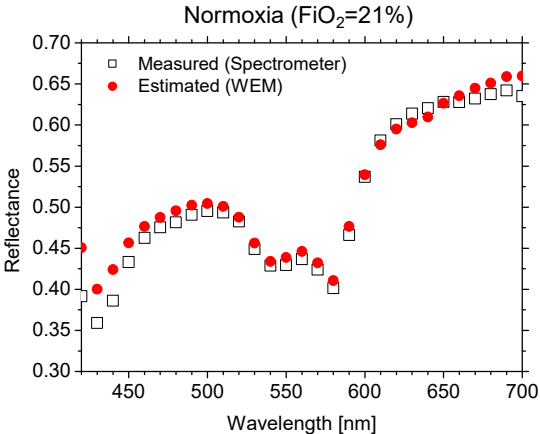

(d)

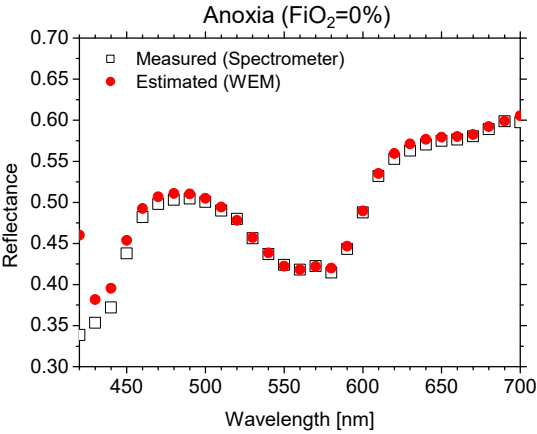

Figure 7. Comparisons of estimated reflectance spectra and reference spectra measured by spectrometer for (a) hyperoxia $\left(\mathrm{FiO}_{2}=40 \%\right)$, (b) normoxia $\left(\mathrm{FiO}_{2}=21 \%\right)$, (c) hypoxia $\left(\mathrm{FiO}_{2}=5 \%\right)$, and (d) anoxia $\left(\mathrm{FiO}_{2}=0 \%\right)$. 
Table 2. Goodness-of-fit coefficient (GFC) obtained from three rats during changes in $\mathrm{FiO}_{2}$.

\begin{tabular}{ccccccc}
\hline \multicolumn{7}{c}{ Goodness-of-Fit Coefficient (GFC) } \\
\hline Rat & Mean & \pm SD & Max & Min & Number of Spectra & Accuracy \\
\hline \#5 & 0.9991 & 0.0002 & 0.9996 & 0.9984 & 191 & Good \\
$\# 6$ & 0.9983 & 0.0003 & 0.9990 & 0.9976 & 191 & Colorimetrically accurate \\
\hline 7 & 0.9981 & 0.0004 & 0.9992 & 0.9969 & 191 & Colorimetrically accurate \\
\hline
\end{tabular}

Figure 8 shows typical sequential images of $\mathrm{C}_{\mathrm{HbT}}, S t \mathrm{O}_{2}$, and $C_{\text {metHb }}$ obtained from rat dorsal skin during changes in $\mathrm{FiO}_{2}$. Figure 9 shows the time courses of (a) $\mathrm{C}_{\mathrm{HbT}}$, (b) $\mathrm{tStO}_{2}$, and (c) $\mathrm{C}_{\mathrm{metHb}}$ averaged over the entire region of each image shown in Figure 8 during changes in $\mathrm{FiO}_{2}$. Time courses of percutaneous oxygen saturation $\left(\mathrm{SpO}_{2}\right)$ and pulse distention $(P D)$ are also compared with $\mathrm{StO}_{2}$ and $\mathrm{C}_{\mathrm{HbT}}$, respectively, in Figure 9. The value of $\mathrm{SpO}_{2}$ dropped remarkably when $\mathrm{FiO}_{2}$ was below $15 \%$. Values of $\mathrm{StO}_{2}$ and $\mathrm{C}_{\mathrm{HbT}}$ gradually decreased and increased, respectively, according to reductions in $\mathrm{FiO}_{2}$. The value of $P D$ gradually increased after the onset of hypoxia. In spite of the remarkable changes in $\mathrm{C}_{\mathrm{HbT}}$ and $\mathrm{StO}_{2}$, there was no significant change in $\mathrm{C}_{\text {metHb }}$ during the measurements.

(a)
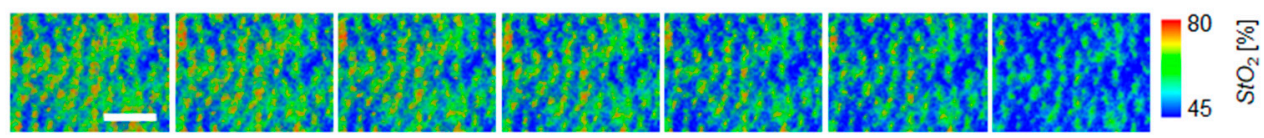

(b)
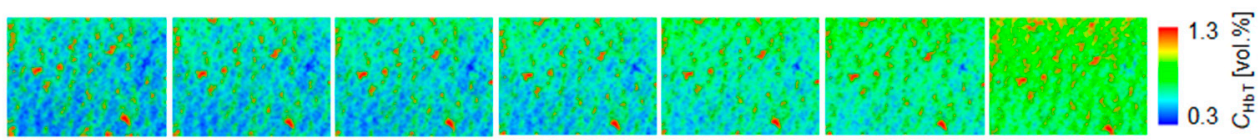

(c)

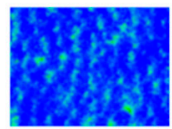

$\mathrm{FiO}_{2}=40 \%$

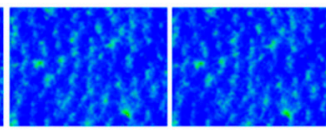

$\mathrm{FiO}_{2}=21 \%$

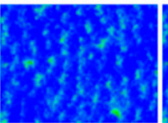

$\mathrm{FiO}_{2}=15 \%$

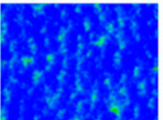

$\mathrm{FiO}_{2}=10 \%$

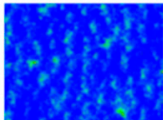

$\mathrm{FiO}_{2}=5 \%$

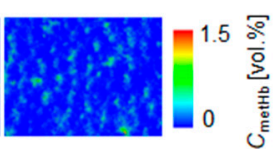

$\mathrm{FiO}_{2}=0 \%$

Figure 8. Typical sequential images of (a) $\mathrm{StO}_{2}$, (b) $\mathrm{C}_{\mathrm{HbT}}$, and (c) $\mathrm{C}_{\text {metHb }}$ obtained from rat dorsal skin during changes in $\mathrm{FiO}_{2}$. A scale bar (white line in the $\mathrm{StO}_{2}$ image for $\mathrm{FiO}_{2}=40 \%$ ) indicates $2.0 \mathrm{~mm}$.

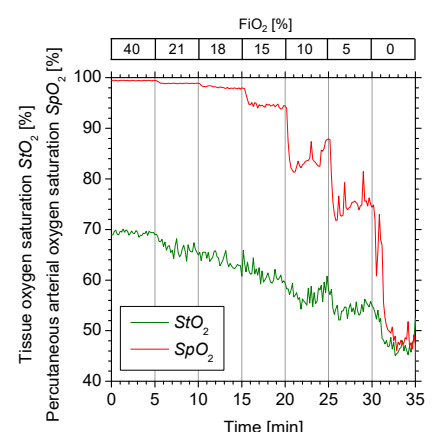

(a)

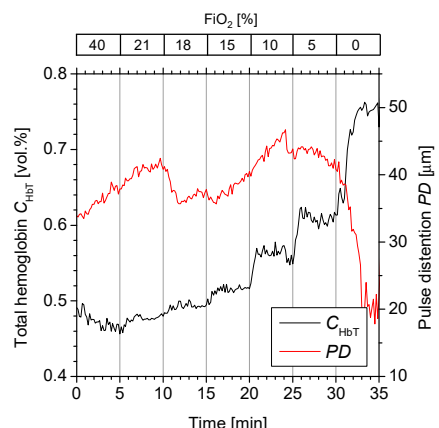

(b)

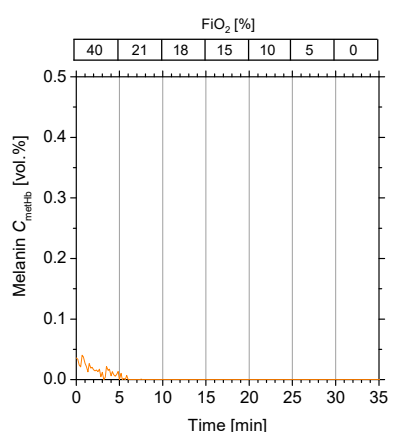

(c)

Figure 9. Typical time courses of (a) $\mathrm{StO}_{2}$, (b) $\mathrm{C}_{\mathrm{HbT}}$, and (c) $\mathrm{C}_{\mathrm{metHb}}$ averaged over entire region of each corresponding image shown in Figure 8. Time courses of $\mathrm{SpO}_{2}$ and $\mathrm{PD}$ were also compared with $\mathrm{StO}_{2}$ and $\mathrm{C}_{\mathrm{HbT}}$, respectively.

Figure 10 shows scatter plots of (a) $\Delta S p \mathrm{O}_{2}$ vs. $\Delta S t \mathrm{O}_{2}$ and (b) $\Delta C_{\mathrm{HbT}}$ vs. $\Delta P D$ obtained from the three rats. As can be seen, the values of $\Delta S t \mathrm{O}_{2}$ and $\Delta \mathrm{C}_{\mathrm{HbT}}$ correlated with those of $S p O_{2}$ and $\triangle P D$, respectively. The correlation coefficient between $\triangle S p O_{2}$ and $\Delta S t O_{2}$ and that between $\Delta C_{\mathrm{HbT}}$ and $\triangle P D$ were $R=0.48(p<0.0001)$ and $R=0.73(p<0.0001)$, indicating that $\mathrm{StO}_{2}$ and $\mathrm{C}_{\mathrm{HbT}}$ were moderately correlated with $\mathrm{SpO}_{2}$ and $P D$, respectively. 

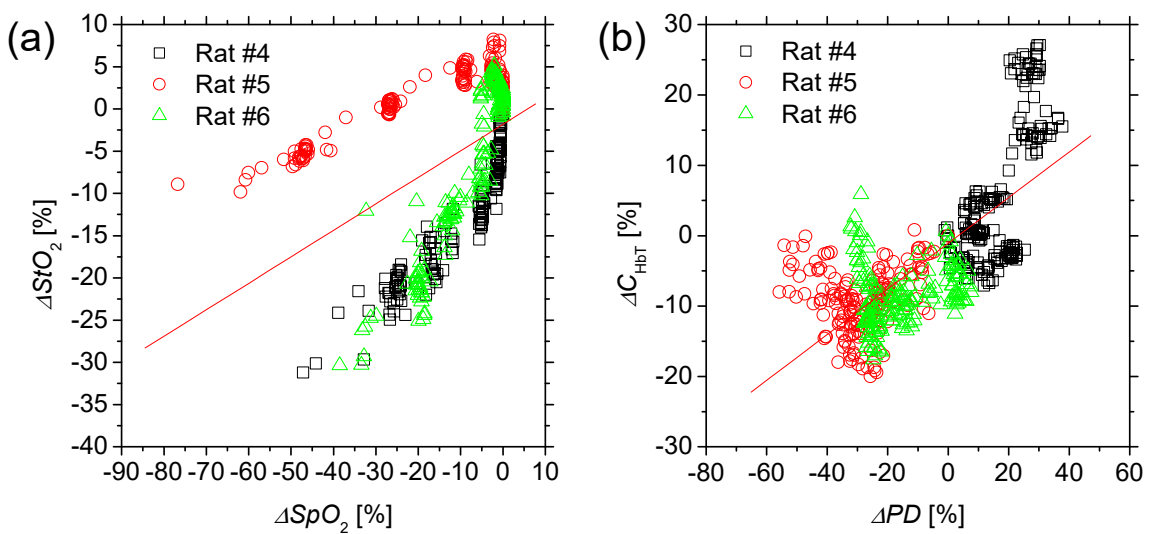

Figure 10. Scatter plots of (a) $\Delta S p \mathrm{O}_{2}$ vs. $\Delta S t \mathrm{O}_{2}$ and (b) $\Delta C_{\mathrm{HbT}}$ vs. $\Delta P D$ obtained from three rats.

\section{Discussion}

In the present study, a model of light transport in skin tissue is applied to analyze the reflectance spectra of rat dorsal skin during methemoglobinemia induced by the administration of $\mathrm{NaNO}_{2}$ and changing the $\mathrm{FiO}_{2}$ using an RGB imaging instrument. With the RGB imaging technique, it was possible to obtain images of oxygenated hemoglobin concentration, deoxygenated hemoglobin concentration, total hemoglobin concentration, and tissue oxygen saturation. The WEM was introduced to reconstruct spectral diffuse reflectance images from an RGB image. The accuracy in spectral reconstruction was validated by comparing the estimated spectra by the WEM with the measured spectra by spectrometer. The results showed that the WEM can present an accurate spectral reconstruction with the average GFC more than 0.998 (Tables 1 and 2). Considering noise in the camera response for $\mathbf{W}$ or using higher order terms of elements in vector $\mathbf{v}$ may improve the accuracy of the WEM $[53,54]$. In this study, we used diffuse reflectance spectra obtained from the skin of albino rats which contained no melanin granules, to establish the matrix W for the WEM. Therefore, we did not confirm the feasibility of the proposed method to evaluate the change in melanin level. When the proposed method is applied to human subjects, the Wiener estimation matrix should be established with diffuse reflectance spectra obtained from the skin of human subjects with different skin phototypes or skin colors.

We examined the hemodynamic responses of rat dorsal skin after the administration of $\mathrm{NaNO}_{2}$. We observed the profound increase in $C_{\text {metHb }}$ after the administration of $\mathrm{NaNO}_{2}$ and the subsequent decrease (Figures $4 \mathrm{a}$ and $5 \mathrm{a}$ ). The time course of $C_{\text {metHb was }}$ indicative of temporary methemoglobinemia. We also observed that the value of $C_{\text {metHb }}$ rapidly increased with a half-maximum time of less than $30 \mathrm{~min}$, and the time required to return to the normal levels increased proportionally with the dose (Figure 6a). The dose-dependent change in $C_{\text {metHb }}$ is compatible with previously reported results [57]. The value of $\mathrm{StO}_{2}$ dramatically dropped at 60 min after the administration of $\mathrm{NaNO}_{2}$, indicating temporary hypoxemia caused by methemoglobinemia, as expected (Figures $4 \mathrm{c}$ and $5 \mathrm{c}$ ). The time required to return to the normal $\mathrm{StO}_{2}$ levels increased proportionally with the dose (Figure $6 \mathrm{c}$ ). The results for $\mathrm{StO}_{2}$ indicated that the proposed method can be used to evaluate peripheral hemoglobin oxygenation level during methemoglobinemia. The value of $C_{\mathrm{HbT}}$ was remarkably increased after the administration of $\mathrm{NaNO}_{2}$ (Figures $4 \mathrm{~b}, 5 \mathrm{~b}$ and $6 \mathrm{~b}$ ). The profound increase in $\mathrm{C}_{\mathrm{HbT}}$ indicated an elevated cardiac output caused by tachycardia during methemoglobinemia [58] and the resultant increase in peripheral blood volume to compensate for the hypoxia and hypoxemia.

We also examined the hemodynamic responses of rat dorsal skin while changing $\mathrm{FiO}_{2}$. We demonstrated that values of $\mathrm{StO}_{2}$ and $\mathrm{C}_{\mathrm{HbT}}$ obtained by the proposed method significantly decreased and increased, respectively, as $\mathrm{FiO}_{2}$ decreased (Figures 8 and 9). Under the normoxia $\left(\mathrm{FiO}_{2}=21 \%\right)$, the average value of $72.6 \pm 4.6 \%$ for $\mathrm{StO}_{2}$ obtained by our method is lower than the average value of $98.8 \pm 0.3 \%$ for $\mathrm{SpO}_{2}$ measured by a pulse oximeter. The value of $\mathrm{StO}_{2}$ estimated by the proposed method represents the oxygen 
saturation for the mixture of arterio-venous blood. Almost $75 \%$ of the total blood volume in the whole body is contained within the veins and venules, whereas $25 \%$ of it is contained within the arteries and arterioles. Assuming that the blood volume ratio of venules and arterioles in the skin tissue is similar to that of the whole body, and the values of arterial oxygen saturation $\mathrm{SaO}_{2}$ and venous oxygen saturation $\mathrm{SvO}_{2}$ under the normoxic condition are $98 \%$ and $75 \%$, respectively, the tissue oxygen saturation of skin is calculated to be $80.6 \%$. This value is close to the average value of $72.6 \pm 4.6 \%$ for $\mathrm{StO}_{2}$, obtained by our method. We observed that the value of $\mathrm{StO}_{2}$ decreased gradually as $\mathrm{FiO}_{2}$ decreased, whereas $\mathrm{SpO}_{2}$ decreased dramatically when $\mathrm{FiO}_{2}$ was below $15 \%$ (Figure 9a). Those changes in both $\mathrm{SpO}_{2}$ and $\mathrm{StO}_{2}$ are due to hypoxemia, which is due to hypoxia. We also observed the profound increase in $P D$ when $\mathrm{FiO}_{2}$ is below $18 \%$ (Figure $9 \mathrm{~b}$ ). The increase in $P D$ is probably due to an elevated cardiac output caused by tachycardia and the resultant increase in peripheral blood volume to compensate for the hypoxia and hypoxemia; this was in agreement with the time course of $C_{\mathrm{HbT}}$ obtained by the proposed method. The time courses of $C_{\mathrm{HbT}}$ and $\mathrm{StO}_{2}$ during changes in $\mathrm{FiO}_{2}$ were consistent with well-known physiological responses to changes in $\mathrm{FiO}_{2}$.

We note that the accuracy of the quantification of each chromophore also depends on the actual thicknesses of the epidermis and the dermis and the light scattering properties of the target skin tissue. In the present study, we assumed the typical thicknesses of the epidermis and the dermis in the MCS to derive the empirical model. The assumed thicknesses of epidermis and the dermis could have an impact on the results of chromophore concentrations. The probability that light is absorbed by melanin in the epidermis will be higher than the probability that light is absorbed by hemoglobin in the dermis as the epidermis becomes thicker. Therefore, if the epidermal thickness is larger than the assumed typical value, melanin in epidermis or hemoglobin derivatives could be under- or overestimated, respectively. The current empirical formulae for chromophores were derived from the MCS with a typical reduced scattering coefficient spectrum derived from the literature data. However, the scattering spectrum usually differs among body parts, and may vary with the age of the subjects. The correct estimation of the scattering properties or consideration of the variations in the scattering spectrum is essential to precisely estimate the chromophore concentrations.

The present method lacks depth resolution, because it relies on the integration of all diffuse reflection information along the depth direction. Moreover, the present method is based on the MCS model, which assumes uniformly distributed scattering and absorption properties. The current algorithm performs multiple regression analysis using each pixel in the spectral image to calculate the multiple regression coefficients. This process is relatively time-consuming, and the computational load increases when the number of pixels in an image for analysis increases. Therefore, this method may not be suitable for real-time high temporal and spatial resolution imaging of chromophores in vivo. The current empirical formulae for chromophores were derived from the MCS with a typical reduced scattering coefficient spectrum. However, the reduced scattering coefficient spectrum usually differs among body parts and may vary with the age of the subjects. Correct estimation of the scattering properties or consideration of the variations in the reduced scattering coefficient spectrum is essential to precisely estimate the chromophore concentrations.

\section{Materials and Methods}

\subsection{Reconstruction of Spectral Image by Wiener Estimation Method}

The response of a digital color camera with spatial coordinates $(x, y)$ with an $i$ th $(i=1$, $2,3)$ color channel, or Red, Green, and Blue, can be calculated as:

$$
v_{i}(x, y)=\int u_{i}(\lambda) E(\lambda) S(\lambda) r(x, y ; \lambda) d \lambda,
$$

where $\lambda$ is the wavelength, $u_{i}(\lambda)$ is the transmittance spectrum of the $i$ th filter, $E(\lambda)$ is the spectrum of the illuminant, $S(\lambda)$ is the sensitivity of the camera, and $r(x, y ; \lambda)$ is the 
reflectance spectrum in the spatial coordinates $(x, y)$. For convenience, Equation (1) is expressed in discrete vector notation as:

$$
\mathbf{v}=\mathbf{F r},
$$

where $\mathbf{v}$ is a vector with a three-element column and $\mathbf{r}$ is a vector with a $k$ element column, which corresponds to the reflectance spectrum of a pixel of an image. $\mathbf{F}$ is a $3 \times k$ matrix and is expressed as:

$$
\mathbf{F}=\mathbf{U E S},
$$

where $\mathbf{U}=\left[\mathrm{u}_{1}, \mathrm{u}_{2}, \mathrm{u}_{3}\right]^{T}$. Column vector $u_{i}$ denotes the transmittance spectrum of the $i$ th filter and [ $]^{T}$ represents the transposition of a vector. $\mathbf{E}$ and $\mathbf{S}$ are $k \times k$ diagonal matrices and represent the spectrum of the illuminant and the sensitivity of the camera, respectively. In this study, we use the known spectral profiles of the illuminant and camera published by the manufacturers. The Wiener estimation of $\mathbf{r}$ is given by:

$$
\tilde{\mathbf{r}}=\mathbf{W v},
$$

where $\mathbf{W}$ is the Wiener estimation matrix. The purpose of $\mathbf{W}$ is to minimize the least squares error between the original and estimated reflectance spectra. In this case, the least squares error is expressed as:

$$
e=\left\langle(\mathbf{r}-\tilde{\mathbf{r}})^{t}(\mathbf{r}-\tilde{\mathbf{r}})\right\rangle,
$$

From Equations (4) and (5), the least squares error is rewritten as:

$$
e=\left\langle(\mathbf{r}-\tilde{\mathbf{r}})^{t}(\mathbf{r}-\tilde{\mathbf{r}})\right\rangle=\left\langle\mathbf{r}^{t} \mathbf{r}\right\rangle-\mathbf{W}\left\langle\mathbf{r}^{t} \mathbf{v}\right\rangle-\mathbf{W}^{t}\left\langle\mathbf{v}^{t} \mathbf{r}\right\rangle+\mathbf{W}^{t} \mathbf{W}\left\langle\mathbf{v}^{t} \mathbf{v}\right\rangle,
$$

The minimization of the least squares error requires that the partial derivative of $e$ with respect to $\mathbf{W}$ is zero as:

$$
\frac{\partial e}{\partial \mathbf{W}}=-\left\langle\mathbf{r}^{t} \mathbf{v}\right\rangle+\mathbf{W}^{t}\left\langle\mathbf{v}^{t} \mathbf{v}\right\rangle=0,
$$

From Equation (7), the matrix $\mathrm{W}$ is derived as:

$$
\mathbf{W}=\langle\mathbf{r v} T\rangle\left\langle\mathbf{v} \mathbf{v}^{T}\right\rangle^{-1}=\langle\mathbf{r v} T\rangle \mathbf{F}^{T}\left(\mathbf{F}\left\langle\mathbf{r r} \mathbf{r}^{T}\right\rangle \mathbf{F}^{T}\right)^{-1},
$$

where \langle\rangle is an ensemble-averaging operator. To derive the matrix $\mathbf{W}$, the autocorrelation matrix $\left\langle\mathbf{r r}^{T}\right\rangle$ is required. In this study, we determined $\left\langle\mathbf{r r}^{T}\right\rangle$ on the basis of 440 different reflectance spectra obtained from rat dorsal skin under various physiological conditions. Discrete reflectance values ranging from 420 to $700 \mathrm{~nm}$ at $10 \mathrm{~nm}$ intervals were extracted from the raw reflectance spectrum measured by the spectrometer and assigned to the 29 elements of vector $\mathbf{r}$. A matrix $\mathbf{r r}^{T}$ with $29 \times 29$ elements was derived by multiplying the vector $\mathbf{r}$ and its transposition vector $\mathbf{r}^{T}$. This procedure was applied to each reflectance sample and 440 different matrices of $\mathbf{r r}^{T}$ were derived. The autocorrelation matrix $\left\langle\mathbf{r r}{ }^{T}\right\rangle$ was calculated by averaging the corresponding elements over all samples.

\subsection{Estimation of Chromophores Based on Multiple Regression Analysis}

We modified the approach proposed by Nishidate et al. [56], which was designed to quantify the three major chromophores of oxygenated hemoglobin, deoxygenated hemoglobin, and melanin. In this study, we considered the four chromophores of methe- 
moglobin, oxygenated hemoglobin, deoxygenated hemoglobin, and melanin in the skin tissue model. The absorbance spectrum $A(\lambda)$ was defined as

$$
A(\lambda)=\log _{10} \frac{1}{r(\lambda)}
$$

where $r(\lambda)$ is the diffuse reflectance spectrum normalized by the incident light spectrum. Because attenuation due to light scattering can be treated as a pseudochromophore [59,60], the attenuation spectrum $A(\lambda)$ can be approximated as the sum of attenuations due to absorption and scattering in the skin tissue, as follows:

$$
\begin{aligned}
A(\lambda) & =C_{\mathrm{metHb}} l_{d}\left(\lambda, C_{\mathrm{metHb}}, C_{\mathrm{HbO}}, C_{\mathrm{HbR}}, \mu_{s}{ }^{\prime}\right) \varepsilon_{\mathrm{metHb}}(\lambda) \\
& +C_{\mathrm{HbO}} l_{d}\left(\lambda, C_{\mathrm{metHb}}, C_{\mathrm{HbO}}, C_{\mathrm{HbR}}, \mu_{s}^{\prime}\right) \varepsilon_{\mathrm{HbO}}(\lambda) \\
& +C_{\mathrm{HbR}} l_{d}\left(\lambda, C_{\mathrm{metHb}}, C_{\mathrm{HbO}}, C_{\mathrm{HbR}}, \mu_{s}^{\prime}\right)^{\prime} \varepsilon_{\mathrm{HbR}}(\lambda) \\
& +C_{\mathrm{m}} l_{e}\left(\lambda, C_{\mathrm{m}}, \mu_{s}^{\prime}\right) \varepsilon_{\mathrm{m}}(\lambda)+S\left(\lambda, \mu_{s}^{\prime}\right)
\end{aligned}
$$

where $C$ is the concentration, $l$ is the mean path length, $\varepsilon(\lambda)$ is the extinction coefficient, and $S\left(\lambda, \mu_{s}{ }^{\prime}\right)$ indicates attenuation due to light scattering in the tissue. The subscripts met $\mathrm{Hb}, \mathrm{HbO}, \mathrm{HbR}$, and $\mathrm{m}$ indicate methemoglobin, oxygenated hemoglobin, deoxygenated hemoglobin, and melanin, respectively. By using $A(\lambda)$ at $\lambda=500$ to $650 \mathrm{~nm}$ at $10 \mathrm{~nm}$ intervals, as the response variable and $\varepsilon(\lambda)$ in the same wavelength range as the predictor variables, the multiple regression analysis can be performed as

$$
A(\lambda)=a_{\mathrm{metHb}} \varepsilon_{\mathrm{metHb}}(\lambda)+a_{\mathrm{HbO}} \varepsilon_{\mathrm{HbO}}(\lambda)+a_{\mathrm{HbR}} \varepsilon_{\mathrm{HbR}}(\lambda)+a_{\mathrm{m}} \varepsilon_{\mathrm{m}}(\lambda)+a_{0}
$$

where $a_{\mathrm{metHb}}, a_{\mathrm{HbO}}, a_{\mathrm{HbR}}, a_{\mathrm{m}}$, and $a_{0}$ are the regression coefficients. We refer to this multiple regression analysis as MRA1. The multiple regression coefficients $a_{\mathrm{metHb}}, a_{\mathrm{HbO}}$, $a_{\mathrm{HbR}}$, and $a_{\mathrm{m}}$ describe the degree of contribution of $\varepsilon_{\mathrm{metHb}}(\lambda), \varepsilon_{\mathrm{HbO}}(\lambda), \varepsilon_{\mathrm{HbR}}(\lambda)$, and $\varepsilon_{\mathrm{m}}(\lambda)$, respectively, to $A(\lambda)$. Therefore, the values of $a_{\mathrm{metHb}}, a_{\mathrm{HbO}}, a_{\mathrm{HbR}}$, and $a_{\mathrm{m}}$ are closely related to $C_{\mathrm{metHb}}, C_{\mathrm{HbO}}, C_{\mathrm{HbR}}$, and $C_{\mathrm{m}}$, respectively. We used the multiple regression coefficients $a_{\mathrm{metHb}}, a_{\mathrm{HbO}}, a_{\mathrm{HbR}}, a_{\mathrm{m}}$, and $a_{0}$ to estimate the concentrations of $C_{\mathrm{metHb}}, C_{\mathrm{HbO}}, C_{\mathrm{HbR}}$, and $C_{\mathrm{m}}$. For this purpose, we assumed the empirical formulae for $C_{\mathrm{metHb}}, C_{\mathrm{HbO}}, C_{\mathrm{HbR}}$, and $C_{\mathrm{m}}$ as

$$
\begin{aligned}
C_{\mathrm{metHb}} & =\mathbf{b}_{\mathbf{m e t H b}} \cdot \mathbf{a} \\
C_{\mathrm{HbO}} & =\mathbf{b}_{\mathrm{HbO}} \cdot \mathbf{a} \\
C_{\mathrm{HbR}} & =\mathbf{b}_{\mathrm{HbR}} \cdot \mathbf{a} \\
C_{\mathrm{m}} & =\mathbf{b}_{\mathbf{m}} \cdot \mathbf{a}
\end{aligned}
$$

where

$$
\begin{gathered}
\mathbf{a}=\left[1, a_{\mathrm{metHb}}, a_{\mathrm{HbO}}, a_{\mathrm{HbR}}, a_{\mathrm{m}}, a_{0}, \cdots \text { higher order terms } \cdots\right]^{\mathrm{T}} \\
\mathbf{b}_{\mathbf{m e t H b}}=\left[b_{\mathrm{metHb}, 0}, b_{\mathrm{metHb}, 1}, b_{\mathrm{metHb}, 2}, \cdots, b_{\mathrm{metHb}, z-1}\right] \\
\mathbf{b}_{\mathrm{HbO}}=\left[b_{\mathrm{HbO}, 0}, b_{\mathrm{HbO}, 1}, b_{\mathrm{HbO}, 2}, \cdots, b_{\mathrm{HbO}, z-1}\right] \\
\mathbf{b}_{\mathrm{HbR}}=\left[b_{\mathrm{HbR}, 0}, b_{\mathrm{HbR}, 1}, b_{\mathrm{HbR}, 2} \cdots, b_{\mathrm{HbR}, z-1}\right] \\
\mathbf{b}_{\mathbf{m}}=\left[b_{\mathrm{m}, 0}, b_{\mathrm{m}, 1}, b_{\mathrm{m}, 2}, \cdots, b_{\mathrm{m}, z-1}\right]
\end{gathered}
$$

The symbol [ ] $]^{\mathrm{T}}$ represents the transposition of a vector. The coefficient vectors $\mathbf{b}_{\text {metHb}}$, $\mathbf{b}_{\mathrm{HbO}}, \mathbf{b}_{\mathrm{HbR}}$, and $\mathbf{b}_{\mathrm{m}}$ are unknown and must be determined before estimating $C_{\mathrm{metHb}}$, $C_{\mathrm{HbO}}, C_{\mathrm{HbR}}$, and $C_{\mathrm{m}}$. The number of components in vectors $\mathbf{a}, \mathbf{b}_{\mathrm{metHb}}, \mathbf{b}_{\mathrm{HbO}}, \mathbf{b}_{\mathrm{HbR}}$, and $\mathbf{b}_{\mathrm{m}}$ is assumed to be $z$. We conducted further multiple regression analyses to establish the vectors $\mathbf{b}_{\mathrm{metHb}}, \mathbf{b}_{\mathrm{HbO}}, \mathbf{b}_{\mathrm{HbR}}$, and $\mathbf{b}_{\mathrm{m}}$. In this second multiple regression analysis, $C_{\mathrm{metHb}}, C_{\mathrm{HbO}}, C_{\mathrm{HbR}}$, and $C_{\mathrm{m}}$ were regarded as dependent variables, and the five regression coefficients $\left(a_{\mathrm{metHb}}, a_{\mathrm{HbO}}, a_{\mathrm{HbR}}, a_{\mathrm{m}}\right.$, and $\left.a_{0}\right)$ that were obtained from MRA1 were regarded 
as independent variables to determine the regression equations for $C_{\mathrm{metHb}}, C_{\mathrm{HbO}}, C_{\mathrm{HbR}}$, and $C_{\mathrm{m}}$. We refer to this analysis as MRA2.

We simulated the diffuse reflectance spectra of skin tissues by using the MCS for light transport ${ }^{38}$ to derive the datasets of chromophore concentrations and the multiple regression coefficients $a_{\mathrm{metHb}}, a_{\mathrm{HbO}}, a_{\mathrm{HbR}}, a_{\mathrm{m}}$, and $a_{0}$. The simulation model consisted of two layers representing the epidermis and dermis. In total, 5,000,000 photon packets were launched in a single simulation of diffuse reflectance at each wavelength. The absorption coefficients for oxygenated hemoglobin $\mu_{a, \mathrm{HbO}}(\lambda)$, deoxygenated hemoglobin $\mu_{a, \mathrm{HbR}}(\lambda)$, methemoglobin $\mu_{a, \text { metHb}}(\lambda)$, and melanin $\mu_{a, \mathrm{~m}}(\lambda)$ were obtained from the values of $\varepsilon_{\mathrm{HbO}}(\lambda), \varepsilon_{\mathrm{HbR}}(\lambda), \varepsilon_{\mathrm{metHb}}(\lambda)$, and $\varepsilon_{\mathrm{mel}}(\lambda)$, shown in Figure 1 . The absorption coefficients for the epidermis for 10 different melanin concentrations were input for the epidermis layer in the MCS as $C_{\mathrm{m}}=1$ to 10 vol. $\%$ at 1 vol. $\%$ intervals. We assumed that whole blood with $150 \mathrm{~g} / \mathrm{L}$ of hemoglobin is $100 \%$ volume concentration of total hemoglobin $\left(C_{\mathrm{HbT}}=100\right.$ vol. $\left.\%\right)$. The sum of the absorption coefficients for oxygenated hemoglobin $\mu_{a, \mathrm{HbO}}(\lambda)$, deoxygenated hemoglobin $\mu_{a, \mathrm{HbR}}(\lambda)$, and methemoglobin $\mu_{a \text {, metHb }}(\lambda)$ represents the absorption coefficients for total hemoglobin $\mu_{a, \mathrm{HbT}}(\lambda)$. The absorption coefficients for total hemoglobin $\mu_{a, \mathrm{HbT}}(\lambda)$ for the values of $C_{\mathrm{HbT}}=0.2$ to $1.0 \mathrm{vol} . \%$ at 0.2 vol. $\%$ intervals were input for the dermis layer in the MCS. Tissue oxygen saturation $\left(\mathrm{StO}_{2}\right)$ was determined by $\mu_{a, \mathrm{HbO}}(\lambda) / \mu_{a, \mathrm{HbT}}(\lambda)$ and values ranging from $0 \%$ to $100 \%$ were used for the simulation. The refractive index for the epidermis and dermis layers was assumed to be the same and was fixed at 1.4. The thicknesses of the epidermis and dermis layers were set to 0.06 and $4.94 \mathrm{~mm}$, respectively. The reduced scattering coefficient $\mu_{s}{ }^{\prime}(\lambda)$ calculated from typical values for the scattering coefficient $\mu_{s}(\lambda)$ [41] and anisotropy factor $g(\lambda)$ [41] were used for both the epidermis and dermis layers. In total, 1550 diffuse reflectance spectra at $\lambda=500$ to $650 \mathrm{~nm}$ at $10 \mathrm{~nm}$ intervals were simulated under the various combinations of $C_{\mathrm{metHb}}$, $C_{\mathrm{HbO}}, C_{\mathrm{HbR}}$, and $C_{\mathrm{m}}$. The MRA1 analysis for each simulated spectrum generated 1550 sets of vector $\mathbf{a}$ and concentrations of $C_{\mathrm{metHb}}, C_{\mathrm{HbO}}, C_{\mathrm{HbR}}$, and $C_{\mathrm{m}}$. The coefficient vectors $\mathbf{b}_{\mathrm{metHb}}, \mathbf{b}_{\mathrm{HbO}}, \mathbf{b}_{\mathrm{HbR}}$, and $\mathbf{b}_{\mathrm{m}}$ were determined statistically by performing MRA2. Once $\mathbf{b}_{\mathrm{metHb}}, \mathbf{b}_{\mathrm{HbO}}, \mathbf{b}_{\mathrm{HbR}}$, and $\mathbf{b}_{\mathrm{m}}$ were obtained, $C_{\mathrm{metHb}}, C_{\mathrm{HbO}}, C_{\mathrm{HbR}}$, and $C_{\mathrm{m}}$ were calculated from $a_{\mathrm{metHb}}, a_{\mathrm{HbO}}, a_{\mathrm{HbR}}, a_{\mathrm{m}}$, and $a_{0}$, which were derived from MRA1 for the measured reflectance spectrum.

\subsection{Imaging System}

Figure 11 shows a schematic illustration of the experimental system used in this study. A white light emitting diode (LED) (LA-HDF158A, Hayashi Watch Works Co., Ltd., Tokyo, Japan) illuminated the skin surface via a light guide and a ring-shaped illuminator with a polarizer. Diffusely reflected light was received by a 24-bit RGB CCD camera (DFK-21BF618.H, Imaging Source LLC, Charlotte, NC, USA) with a zoom lens and an analyzer to acquire an RGB image of $640 \times 480$ pixels. The primary polarization plate (ring-shaped polarizer) and the secondary polarization plate (analyzer) were set to be in a crossed Nicols alignment in order to reduce specular reflection from the skin surface. A standard white diffuser with 99\% reflectance (SRS-99-020; Labsphere, North Sutton, NH, USA) was used to regulate the camera white balance. To evaluate the accuracy of the WEM, the reflectance spectra of skin were simultaneously measured by a fiber-coupled spectrometer (USB4000-XRS-ES, Ocean Optics Inc., Dunedin, FL, USA) with an integration time of $80 \mathrm{~ms}$ as reference data. Before the sequential measurements of RGB images and reflectance spectra, the area measured by the spectrometer was confirmed by projecting light from a halogen lamp (HL-2000, Ocean Optics Inc., Dunedin, FL, USA) onto the skin surface via one lead of a bifurcated fiber, lens, and beam splitter. The RGB image of the skin surface including the spot of light illuminated by the halogen lamp was stored on the PC, and then the size and coordinates of the spot were specified as the area measured by the spectrometer. After the halogen lamp was turned off, sequential measurements of RGB images and reflectance spectra were simultaneously performed. The region of interest (ROI) on the image of the skin surface was selected to be the same as the area 
measured by the spectrometer. Using the WEM, reflectance images ranging from 420 to $700 \mathrm{~nm}$ at intervals of $10 \mathrm{~nm}$ were reconstructed from the RGB image acquired at $30 \mathrm{~ms}$ of exposure time. This means that spectral images at 29 wavelengths can be obtained with a temporal resolution of $15 \mathrm{fps}$. Images at 16 wavelengths (500 to $650 \mathrm{~nm}$ at intervals of $10 \mathrm{~nm}$ ) were then used to estimate the $C_{\mathrm{metHb}}, C_{\mathrm{HbO}}, C_{\mathrm{HbR}}$, and $C_{\mathrm{m}}$ images according to the above process.

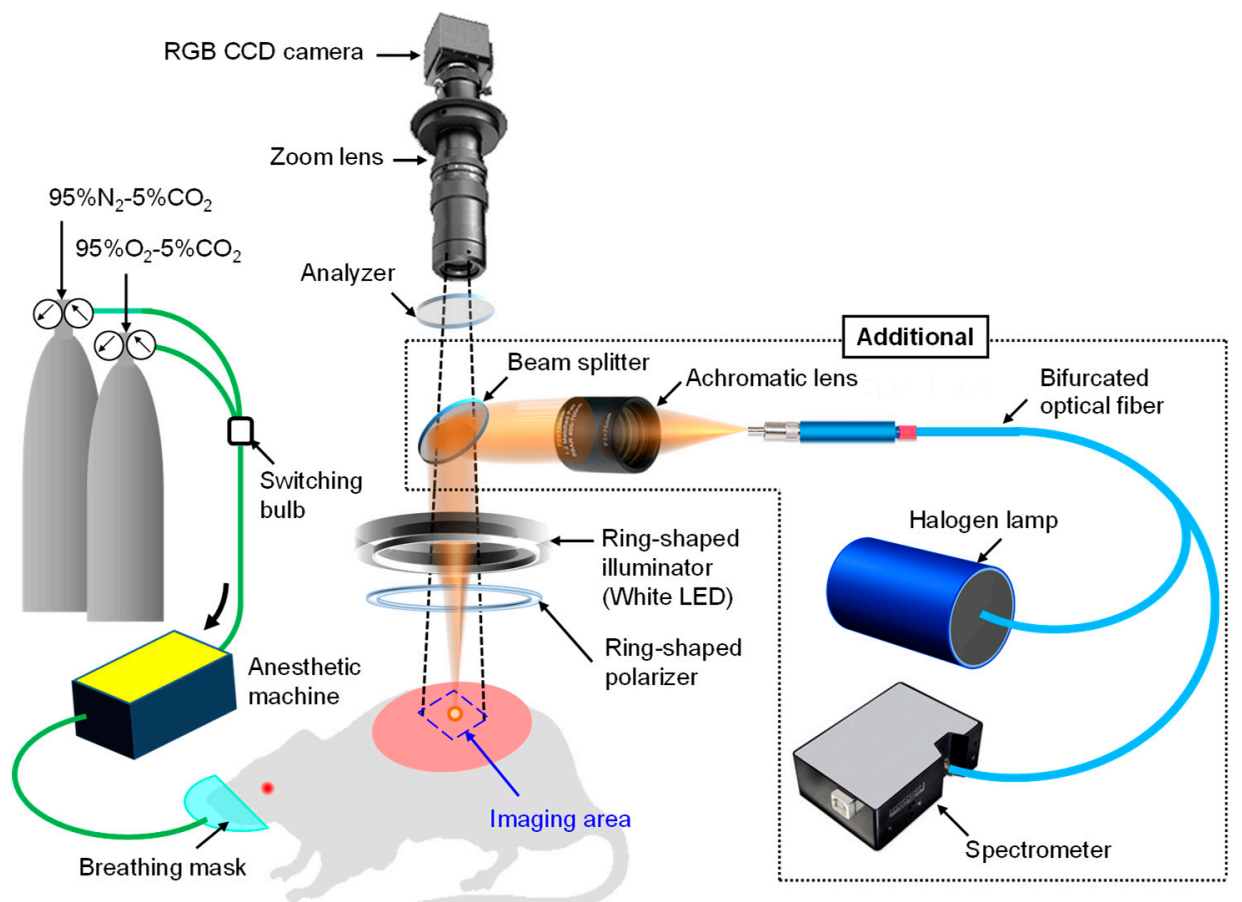

Figure 11. Schematic diagram of experimental configuration for image acquisitions and the spectral reflectance measurements.

\subsection{Animal Experiments}

Male Wister rats $(n=7)$ weighing 470 to $640 \mathrm{~g}$ were used for the animal experiments. All experimental procedures were conducted according to the protocols approved by the Animal Care Committee of Tokyo University of Agriculture and Technology (approval number 31-25, 4 June 2019 and approval number 31-75, 10 February 2020). The anesthesia of rats was performed with isoflurane, and maintained at a depth such that the rat had no response to toe pinching. After the induction of anesthesia, the dorsal region was shaved, and a depilatory agent containing thioglycolic acid was applied to the rat dorsal skin.

First, we performed the measurements with four rats during methemoglobinemia. Rats were administered $\mathrm{NaNO}_{2}$ intraperitoneally at two different dose conditions of 37.5 and $50 \mathrm{mg} / \mathrm{kg}$ body weight (2-mL dosing volume) to induce methemoglobinemia. In the time series measurements during methemoglobinemia, both RGB images and diffuse reflectance spectra were acquired at $60 \mathrm{~s}$ intervals for $360 \mathrm{~min}$. Second, we carried out measurements with three rats while varying the fraction of inspired oxygen $\left(\mathrm{FiO}_{2}\right)$. The value of $\mathrm{FiO}_{2}$ was regulated by mixing $95 \% \mathrm{O}_{2}-5 \% \mathrm{CO}_{2}$ gas and $95 \% \mathrm{~N}_{2}-5 \% \mathrm{CO}_{2}$ gas in an arbitrary ratio. Hyperoxia $\left(\mathrm{FiO}_{2}=40 \%\right)$ was induced by $95 \% \mathrm{O}_{2}-5 \% \mathrm{CO}_{2}$ gas inhalation, for which a breath mask was used under spontaneous respiration, whereas anoxia $\left(\mathrm{FiO}_{2}=0 \%\right)$ was induced by $95 \% \mathrm{~N}_{2}-5 \% \mathrm{CO}_{2}$ gas inhalation. In the time series measurements, while varying $\mathrm{FiO}_{2}$, both RGB images and diffuse reflectance spectra were acquired at $10 \mathrm{~s}$ intervals for $35 \mathrm{~min}$. Simultaneously, with the optical imaging for skin tissue, percutaneous arterial oxygen saturation $\left(\mathrm{SpO}_{2}\right)$ and pulse distention $(\mathrm{PD})$ were measured by a pulse oximeter (MOUSEOX Pulse Oximeter; Star Life Science, Oakmont, PA, USA) as systemic physiological parameters. The amplitude of the light absorption signal, due to the cardiac 
pulse, which corresponded to the change in the distention of the arterial blood vessels at the sensor location, was taken to be the $P D$. This can be used as an indicator of local blood flow or peripheral blood volume.

To evaluate the magnitude of the signal $M$, induced during methemoglobinemia and during changes in $\mathrm{FiO}_{2}$, we calculated the change in the signal based on the time series data. The signal before the administration of $\mathrm{NaNO}_{2}$ or at normoxia was selected as the control $M_{\mathrm{c}}$, which was subtracted from each of the subsequent signals $\mathrm{M}$ in the series. Each subtracted value, which demonstrated the change in the signal, $M-M_{\mathrm{c}}$, over time, was normalized by dividing by $M_{\mathrm{c}}$. The change in the signal is expressed as $\Delta M=\{(M$ $\left.-M_{\mathrm{c}}\right) / M_{\mathrm{c}}$. The above calculation was applied to the time series of $C_{\mathrm{metHb}}, C_{\mathrm{HbO}}, C_{\mathrm{HbR}}$ $\mathrm{C}_{\mathrm{HbT}}, \mathrm{StO}_{2}, \mathrm{C}_{\mathrm{metHb}}, \mathrm{C}_{\mathrm{m}}, \mathrm{SpO}_{2}$ and $\mathrm{PD}$.

\subsection{Statistical Considerations}

We used only one area of each rat for data analysis of spectral images. The region of interest (ROI) of $300 \times 300$ pixels was set in each image and the mean and the standard deviation (SD) over the ROI were calculated for the analysis of time courses in $C_{\mathrm{metHb}}, C_{\mathrm{HbO}}$, $\mathrm{C}_{\mathrm{HbR}}, \mathrm{C}_{\mathrm{HbT}}, \mathrm{StO}_{2}$, and $\mathrm{C}_{\mathrm{m}}$. Therefore, data are expressed as mean $\pm \mathrm{SD}$. To test the accuracy of the spectral reconstruction, the spectrum estimated by the WEM is compared with the spectrum measured by the spectrometer using a goodness-of-fit coefficient (GFC) [59]. The GFC is based on the inequality of Schwartz and is described as:

$$
\mathrm{GFC}=\frac{\left|\sum_{j} r_{\text {mes }}\left(\lambda_{j}\right) r_{\text {est }}\left(\lambda_{j}\right)\right|}{\sqrt{\left|\sum_{j}\left[r_{\text {mes }}\left(\lambda_{j}\right)\right]^{2}\right|} \sqrt{\left|\sum_{j}\left[r_{\text {est }}\left(\lambda_{j}\right)\right]^{2}\right|}}
$$

where $r_{m e s}\left(\lambda_{j}\right)$ is the measured original spectral data at the wavelength $\lambda_{j}$ and $r_{e s t}\left(\lambda_{j}\right)$ is the estimated spectral data at the wavelength $\lambda_{j}$. Hernández-Andrés et al. [61] suggested that colorimetrically accurate $r_{\text {mes }}\left(\lambda_{j}\right)$ requires a GFC $>0.995$; a "good" spectral fit requires a GFC $\geq 0.999$, and GFC $\geq 0.9999$ is necessary for an "excellent" spectral fit.

\section{Conclusions}

In summary, the present study demonstrated the usefulness of a new non-contact imaging method based on spectral reflectance images reconstructed from a single snapshot of an RGB image by WEM for the simultaneous measurements of the percutaneous volume concentrations of methemoglobin, oxygenated hemoglobin, deoxygenated hemoglobin, and tissue oxygen saturation. In vivo experiments with rat dorsal skin before and after the administration of $\mathrm{NaNO}_{2}$ at doses of 37.5 and $50 \mathrm{mg} / \mathrm{kg}$ were performed to induce methemoglobinemia. The methemoglobin concentration rapidly increased with a half-maximum time of less than $20 \mathrm{~min}$, reaching a maximal value nearly $60 \mathrm{~min}$ after the administration of $\mathrm{NaNO}_{2}$. The time required for returning to the normal levels increased proportionally with the dose, which implied that the methemoglobinemia was temporary. The values of tissue oxygen saturation significantly dropped after the administration of $\mathrm{NaNO}_{2}$, and then gradually increased for each dose condition, indicating temporary hypoxemia caused by methemoglobinemia. Time courses of total hemoglobin concentration and tissue oxygen saturation, while changing the fraction of inspired oxygen, coincided with well-known physiological responses to hyperoxia, normoxia, and hypoxia, which demonstrates the feasibility of using this method for monitoring changes in skin hemodynamics due to loss of tissue viability and vitality. The great advantages of this method are its simplicity and applicability, because the only devices required are a digital RGB image sensor with a known color profile, a white light source, and a personal computer. 
Author Contributions: Conceptualization, I.N.; methodology, Y.A. and I.N.; validation, F.K.; formal analysis, F.K.; data curation, F.K. and I.N.; writing—original draft preparation, F.K.; writing—review and editing, Y.A. and I.N.; supervision, I.N.; project administration, I.N.; funding acquisition, I.N. All authors have read and agreed to the published version of the manuscript.

Funding: Part of this work was supported by JSPS KAKENHI Grant Number 17H06102.

Institutional Review Board Statement: The study was conducted according to the guidelines of the Declaration of Helsinki and approved by the Animal Care Committee of Tokyo University of Agriculture and Technology (approval number 31-25, 4 June 2019 and approval number 31-75, 10 February 2020).

Conflicts of Interest: The authors declare no conflict of interest.

\section{References}

1. Baernstein, A.; Smith, K.; Elmore, J. Singing the blues: Is it really cyanosis? Resp. Care 2008, 53, 1081-1084.

2. Stephen, W.A.; Gladimir, V.G.B. On the dysfunctional hemoglobins and cyanosis connection: Practical implications for the clinical detection and differentiation of methemoglobinemia and sulfhemoglobinemia. Biomed. Opt. Express 2018, 9, $3284-3305$. [CrossRef]

3. Casey, G. Oxygen transport and the use of pulse oxymetry. Nurs. Stand. 2001, 15, 46-53. [CrossRef] [PubMed]

4. Baranoski, G.V.G.; Van Leeuwen, S.R.; Chen, T.F. Elucidating the biophysical processes responsible for the chromatic attributes of peripheral cyanosis. In Proceedings of the 2017 39th Annual International Conference of the IEEE Engineering in Medicine and Biology Society (EMBC), Jeju Island, Korea, 11 July 2017; pp. 90-95.

5. McMullen, S.M.; Patrick, W. Cyanosis. Am. J. Med. 2013, 126, 210-212. [CrossRef] [PubMed]

6. Haymond, S.; Cariappa, R.; Eby, C.S.; Scott, M.G. Laboratory Assessment of Oxygenation in Methemoglobinemia. Clin. Chem. 2005, 51, 434-444. [CrossRef]

7. Lundsgaard, C.; Slyke, D.V. Cyanosis. In Medicine Monographs; The Rockfeller Institute for Medical Research, Wlliams \& Wilkins Company: Philadelphia, PA, USA, 1923; pp. 1-80.

8. Camp, N.E. Methemoglobinemia. J. Emerg. Nurs. 2007, 33, 172-174. [CrossRef]

9. Bradberry, S. Methaemoglobinaemia. Medicine 2012, 40, 59-60. [CrossRef]

10. Prahl, S.A. Tabulated Molar Extinction Coefficient for Hemoglobin in Water. 1999. Available online: http://omlc.ogi.edu/spectra/ hemoglobin/summary.html (accessed on 20 December 2020).

11. Zijlstra, W.; Buursma, A. Spectrophotometry of Hemoglobin: Absorption Spectra of Bovine Oxyhemoglobin, Deoxyhemoglobin, Carboxyhemoglobin, and Methemoglobin. Comp. Biochem. Physiol. 1997, 118, 743-749. [CrossRef]

12. Jacques, S.L.; Glickman, R.D.; Schwartz, J.A. Internal absorption coefficient and threshold for pulsed laser disruption of melanosomes isolated from retinal pigment epithelium. Proc. SPIE 1996, 2681, 468-477. [CrossRef]

13. Baranoski, G.V.G.; Chen, T.F.; Kimmel, B.W.; Miranda, E.; Yim, D. On the noninvasive optical monitoring and differentiation of methemoglobinemia and sulfhemoglobinemia. J. Biomed. Opt. 2012, 17, 0970051-09700514. [CrossRef]

14. Kohn, M.C.; Melnick, R.L.; Ye, F.; Portier, C.J. Pharmacokinetics of Sodium Nitrite-Induced Methemoglobinemia in the Rat. Drug Metab. Dispos. 2002, 30, 676-683. [CrossRef] [PubMed]

15. Groeper, K.; Katcher, K.; Tobias, J.D. Anesthetic Management of a Patient with Methemoglobinemia. South. Med J. 2003, 96, 504-509. [CrossRef] [PubMed]

16. Umbreit, J. Methemoglobin-It's not just blue: A concise review. Am. J. Hematol. 2007, 82, 134-144. [CrossRef] [PubMed]

17. Bradberry, S. Methaemoglobinaemia: Complications of poisoning. Medicine 2016, 44, 91-92. [CrossRef]

18. Percy, M.J.; McFerran, N.V.; Lappin, T.R. Disorders of oxidised haemoglobin. Blood Rev. 2005, 19, 61-68. [CrossRef] [PubMed]

19. Da-Silva, S.S.; Sajan, I.S.; Underwood, J.P. Congenital Methemoglobinemia: A Rare Cause of Cyanosis in the Newborn-A Case Report. Pediatrics 2003, 112, e158-e161. [CrossRef]

20. Kern, K.; Langevin, P.B.; Dunn, B.M. Methemoglobinemia after topical anesthesia with lidocaine and benzocaine for a difficult intubation. J. Clin. Anesth. 2000, 12, 167-172. [CrossRef]

21. Singh, R.K.; Kambe, J.C.; Andrews, L.K.; Russell, J.C. Benzocaine-Induced Methemoglobinemia Accompanying Adult Respiratory Distress Syndrome and Sepsis Syndrome: Case Report. J. Trauma 2001, 50, 1153-1157. [CrossRef]

22. Udeh, C.; Bittikofer, J.; Sum-Ping, S. Severe methemoglobinemia on reexposure to benzocaine. J. Clin. Anesth. 2001, 13, 128-130. [CrossRef]

23. Tang, A.S.O.; Yeo, S.T.; Teh, Y.C.; Kho, W.M.; Chew, L.P.; Muniandy, P. The mystery of 'saturation gap': A case of dapsone-induced methaemoglobinemia in a pregnant mother with leprosy. Oxf. Med. Case Rep. 2019, 2019, omy111. [CrossRef]

24. Harvey, M.; Cave, G.; Chanwai, G. Fatal methaemoglobinaemia induced by self-poisoning with sodium nitrite. Emerg. Med. Australas. 2010, 22, 463-465. [CrossRef]

25. World Health Organization. Nitrate and Nitrite in Drinking-Water; WHO/FWC/WSH/16.52; World Health Organization: Geneva, Switzerland, 2016.

26. Rehman, H.U. Methemoglobinemia. West. J. Med. 2001, 175, 193-196. [CrossRef] 
27. Ginimuge, P.R.; Jyothi, S. Methylene Blue: Revisited. J. Anaesthesiol. Clin. Pharmacol. 2010, 26, 517-520.

28. Patnaik, S.; Natarajan, M.; James, E.; Ebenezer, K. Methylene blue unresponsive methemoglobinemia. Indian J. Crit. Care Med. 2014, 18, 253-255. [CrossRef] [PubMed]

29. Cortazzo, J.A.; Lichtman, A.D. Methemoglobinemia: A Review and Recommendations for Management. J. Cardiothorac. Vasc. Anesth. 2014, 28, 1043-1047. [CrossRef] [PubMed]

30. Giangreco, G.J.; Campbell, D.; Cowan, M.J. A 32-Year-Old Female with AIDS, Pneumocystis jiroveci Pneumonia, and Methemoglobinemia. Case Rep. Crit. Care 2013, 2013, 1-5. [CrossRef]

31. Chan, E.D.; Chan, M.M.; Chan, M.M. Pulse oximetry: Understanding its basic principles facilitates appreciation of its limitations. Respir. Med. 2013, 107, 789-799. [CrossRef] [PubMed]

32. Kirlangitis, J.J.; Middaugh, R.E.; Zablocki, A.; Rodriquez, F. False indication of arterial oxygen desaturation and methemoglobinemia following injection of methylene blue in urological surgery. Mil. Med. 1990, 155, 260-262. [CrossRef] [PubMed]

33. Lee, J.; El-Abaddi, N.; Duke, A.; Cerussi, A.E.; Brenner, M.; Tromberg, B.J. Noninvasive in vivo monitoring of methemoglobin formation and reduction with broadband diffuse optical spectroscopy. J. Appl. Physiol. 2006, 100, 615-622. [CrossRef] [PubMed]

34. Fishkin, J.B.; So, P.T.C.; Cerussi, A.E.; Fantini, S.; Franceschini, M.A.; Gratton, E. Frequency-domain method for measuring spectral properties in multiple-scattering media: Methemoglobin absorption spectrum in a tissuelike phantom. Appl. Opt. 1995, 34, 1143-1155. [CrossRef] [PubMed]

35. Saager, R.B.; Rowland, R.A.; Baldado, M.L.; Kennedy, G.T.; Bernal, N.P.; Ponticorvo, A.; Christy, R.J.; Durkin, A.J. Impact of hemoglobin breakdown products in the spectral analysis of burn wounds using spatial frequency domain spectroscopy. J. Biomed. Opt. 2019, 24, 020501. [CrossRef] [PubMed]

36. Leung, G.; Duta, D.; Perry, J.; Leonardi, L.; Fish, J.; Cross, K. Rapid tissue viability evaluation using methemoglobin as a biomarker in burns. Int. J. Burn. Trauma 2018, 8, 126-134.

37. Tang, M.; Zhou, Y.; Zhang, R.; Wang, L.V. Noninvasive photoacoustic microscopy of methemoglobin in vivo. J. Biomed. Opt. 2015, 20, 036007. [CrossRef] [PubMed]

38. Aizawa, K.; Sato, S.; Saitoh, D.; Ashida, H.; Obara, M. In vivoPhotoacoustic Spectroscopic Imaging of Hemoglobin Derivatives in Thermally Damaged Tissue. Jpn. J. Appl. Phys. 2009, 48, 062302. [CrossRef]

39. Harrison, D.K.; Evans, S.D.; Abbot, N.C.; Beck, J.S.; Mccollum, P.T. Spectrophotometric measurements of haemoglobin saturation and concentration in skin during the tuberculin reaction in normal human subjects. Clin. Phys. Physiol. Meas. 1992, 13, 349-363. [CrossRef] [PubMed]

40. Zonios, G.; Bykowski, J.; Kollias, N. Skin Melanin, Hemoglobin, and Light Scattering Properties can be Quantitatively Assessed In Vivo Using Diffuse Reflectance Spectroscopy. J. Investig. Dermatol. 2001, 117, 1452-1457. [CrossRef]

41. Nishidate, I.; Aizu, Y.; Mishina, H. Estimation of melanin and hemoglobin in skin tissue using multiple regression analysis aided by Monte Carlo simulation. J. Biomed. Opt. 2004, 9, 700-710. [CrossRef]

42. Stratonnikov, A.A.; Loschenov, V.B. Evaluation of blood oxygen saturation in vivo from diffuse reflectance spectra. J. Biomed. Opt. 2001, 6, 457-467. [CrossRef]

43. Nishidate, I.; Wiswadarma, A.; Hase, Y.; Tanaka, N.; Maeda, T.; Niizeki, K.; Aizu, Y. Noninvasive spectral imaging of skin chromophores based on multiple regression analysis aided by Monte Carlo simulation. Opt. Lett. 2011, 36, 3239-3241. [CrossRef]

44. Sowa, M.G.; Payette, J.R.; Hewko, M.; Mantsch, H.H. Visible-Near Infrared Multispectral Imaging of the Rat Dorsal Skin Flap. J. Biomed. Opt. 1999, 4, 474-481. [CrossRef]

45. Dunn, A.K.; Devor, A.; Bolay, H.; Andermann, M.L.; Moskowitz, M.A.; Dale, A.M.; Boas, D.A. Simultaneous imaging of total cerebral hemoglobin concentration, oxygenation, and blood flow during functional activation. Opt. Lett. 2003, 28, 28-30. [CrossRef] [PubMed]

46. Hardeberg, J.Y. Acquisition and Reproduction of Color Images: Colorimetric and Multispectral Approaches. Ph.D. Thesis, Ecole Nationale Superieure des Telecommunications, Paris, France, 1999.

47. Hardeberg, J.Y.; Schmitt, F.; Brettel, H. Multispectral color image capture using liquid crystal tunable filter. Opt. Eng. 2002, 41, 2532-2549. [CrossRef]

48. Cheung, V.; Westland, S.; Li, C.; Hardeberg, J.; Connah, D. Characterization of trichromatic color cameras by using a new multispectral imaging technique. J. Opt. Soc. Am. 2005, 22, 1231-1240. [CrossRef] [PubMed]

49. Shen, H.-L.; Xin, J. Spectral characterization of a color scanner based on optimized adaptive estimation. J. Opt. Soc. Am. 2006, 23, 1566-1569. [CrossRef] [PubMed]

50. Shen, H.-L.; Xin, J.; Shao, S.-J. Improved reflectance reconstruction for multispectral imaging by combining different techniques. Opt. Express 2007, 15, 5531-5536. [CrossRef]

51. König, F. Reconstruction of Natural Spectra from Color Sensor Using Nonlinear Estimation Methods. In Is and T Annual Con-ference; The Society for Imaging Science and Technology: Cambridge, MA, USA, 1997; pp. 454-457.

52. Stigell, P.; Miyata, K.; Hauta-Kasari, M. Wiener estimation method in estimating of spectral reflectance from RGB images. Pattern Recognit. Image Anal. 2007, 17, 233-242. [CrossRef]

53. Murakami, Y.; Fukura, K.; Yamaguchi, M.; Ohyama, N. Color reproduction from low-SNR multispectral images using spatiospectral Wiener estimation. Opt. Express 2008, 16, 4106-4120. [CrossRef] [PubMed] 
54. Chen, S.; Liu, Q. Modified Wiener estimation of diffuse reflectance spectra from RGB values by the synthesis of new colors for tissue measurements. J. Biomed. Opt. 2012, 17, 0305011-0305013. [CrossRef]

55. Shen, H.-L.; Cai, P.-Q.; Shao, S.-J.; Xin, J.H. Reflectance reconstruction for multispectral imaging by adaptive Wiener estimation. Opt. Express 2007, 15, 15545-15554. [CrossRef]

56. Nishidate, I.; Maeda, T.; Niizeki, K.; Aizu, Y. Estimation of Melanin and Hemoglobin Using Spectral Reflectance Images Reconstructed from a Digital RGB Image by the Wiener Estimation Method. Sensors 2013, 13, 7902-7915. [CrossRef]

57. Imaizumi, K.; Tyuma, I.; Imai, K.; Kosaka, H.; Ueda, Y. In vivo studies on methemoglobin formation by sodium nitrite. Int. Arch. Occup. Environ. Health 1980, 45, 97-104. [CrossRef]

58. FDA Drug Safety Communication: FDA Continues to Receive Reports of a Rare, but Serious and Potentially Fatal Adverse Effect with the Use of Benzocaine Sprays for Medical Procedures. April 2011. Available online: https://www.fda.gov/drugs/drugsafety-and-availability / fda-drug-safety-communication-fda-continues-receive-reports-rare-serious-and-potentially-fatal (accessed on 20 November 2020).

59. Kohl, M.; Lindauer, U.; Royl, G.; Kühl, M.; Gold, L.; Villringer, A.; Dirnagl, U. Physical model for the spectroscopic analysis of cortical intrinsic optical signals. Phys. Med. Biol. 2000, 45, 3749-3764. [CrossRef] [PubMed]

60. Jones, P.; Shin, H.K.; Boas, D.A.; Hyman, B.T.; Moskowitz, M.A.; Ayata, C.; Dunn, A.K. Simultaneous multispectral reflectance imaging and laser speckle flowmetry of cerebral blood flow and oxygen metabolism in focal cerebral ischemia. J. Biomed. Opt. 2008, 13, 044007. [CrossRef] [PubMed]

61. Hernández-Andrés, J.; Romero, J. Colorimetric and spectroradiometric characteristics of narrow-field-of-view clear skylight in Granada, Spain. J. Opt. Soc. Am. 2001, A18, 412-420. [CrossRef] 